\title{
Application of a Low Cost Instrumentation in Arctic Extreme Conditions
}

\author{
Viviana Piermattei 1,2, Alice Madonia 1,2, , Simone Bonamano ${ }^{1,2}$, Riccardo Martellucci 1,2, \\ Gabriele Bruzzone ${ }^{3}$, Roberta Ferretti ${ }^{3}$, Angelo Odetti ${ }^{3}$, Maurizio Azzaro ${ }^{4}$, Giuseppe Zappalà 4 \\ and Marco Marcelli 1,2 \\ 1 Laboratory of Experimental Oceanology and Marine Ecology, University of Tuscia, Molo Vespucci, Porto \\ di Civitavecchia, 00053 Civitavecchia (RM), Italy; v.piermattei@unitus.it (V.P.); \\ simo_bonamano@unitus.it(S.B.); riccardo.martellucci@unitus.it(R.M.); marcomarcell@unitus.it(M.M.) \\ 2 Centro Euro-Mediterraneo sui Cambiamenti CLimatici (CMCC), Via Augusto Imperatore, 16, 73100 Lecce, \\ Italy; \\ 3 CNR-ISSIA, Via de Marini, 6, 16149 Genova, Italy; gabriele.bruzzone@ge.issia.cnr.it (G.B.); \\ roberta.ferretti@ge.issia.cnr.it (R.F.); angelo.odetti@ge.issia.cnr.it (A.O.) \\ 4 CNR-IAMC, Spianata S. Raineri, 86, 98122 Messina, Italy; maurizio.azzaro@iamc.cnr.it (M.A.); \\ giuseppe.zappala@iamc.cnr.it (G.Z.) \\ * Correspondence: alice_madonia@unitus.it; Tel.: +39-329-428-752 \\ + Presented at the 4th International Electronic Conference on Sensors and Applications (ECSA 2017), \\ 15-30 November 2017; Available online: https://sciforum.net/conference/ecsa-4.
}

Published: 14 November 2017

\begin{abstract}
Monitoring the Arctic Ocean ecosystem is important to better understand the impact of climate changes on the environment. Large amounts of data are required to monitor physical and biological parameters necessary to feed climatic forecasting models. However there is still a lack of data in the Global Observing System and the development of flexible and low-cost instrumentation is very helpful. A miniaturized temperature, pressure and fluorescence probe, expressly developed to be easily integrated in different platforms, was preliminary installed on an unmanned marine vehicle during a scientific campaign in the Svalbard Archipelago in the framework of UVASS project.
\end{abstract}

Keywords: Arctic ocean; low-cost technology; fluorescence of chlorophyll $a$

\section{Introduction}

Over the last few decades, polar oceans have exhibited some of the most striking impacts of global cLimate change, with temperatures and acidities changing at more than twice the global average. [1]. This enters in a complex system of cLimatic phenomena that led to the drastic decrease of Arctic Sea Ice (about $40 \%$ of reduction in the last decade) that is foreseen will bring to a rapid disappearance [2].The ongoing retreat of Arctic sea ice is exposing increasingly large surface areas of the basin to sunlight and thus promoting increased growth of phytoplankton during summer months [3] . Changes in phytoplankton communities and biomass have been reported by many authors and cLimate change scenarios are predicted to generate longer-lasting bloom windows [4] [5]. The changes in physical and biological processes observed across the entire region may exert strong feedback on atmospheric and oceanic dynamics at global scales. To this respect, the Svalbard represent a border area between Atlantic and Arctic biogeographic zones, where the glacial input of freshwater and sediments create environmental gradients inducing large changes in community composition [6]. Therefore, Svalbard can serve as an optimal Arctic research environment where it is possible to follow ecological changes, also because of the international polar research base of $\mathrm{Ny}$ Ålesund [7]. Moreover, the Kongsfjorden area is relatively warmer than other Arctic areas and a series of processes, such as glacial melt and freshwater influx, influences phytoplankton biomass and 
composition [8]. Though the Arctic ocean is considered a key indicator of cLimate change it is poorly studied and significant gaps still remain in the Global Ocean Observing System. The region is not well covered by satellites and heavy cloud cover often limits their use. Shifting ice and icebergs make it difficult to deploy sea surface equipment over long periods and restrict access for research vessels [9].

Technological advances in oceanographic measurement capabilities are fundamental to observe and monitor changes in the marine ecosystems, particularly in difficult-to-reach regions, improving operational and forecasting oceanography. The development of flexible, adaptable and low-cost instrumentation plays a key role in marine environmental studies, especially for the monitoring of extreme environments like the polar ones. Low-cost and easily adaptable instruments considerably reduce the costs of oceanographic surveys, improving data coverage to study with detail marine environment [10]. In this framework, a miniaturized and flexible probe was developed to be easily integrated in different type of platforms, enabling the continuous measurement of temperature, pressure, fluorescence of chlorophyll $a$, pitch, roll and acceleration. This work presents the preliminary results of its use within the UVASS (Unmanned Vehicles for Autonomous Sensing and Sampling) research project, in the Svalbard Archipelago.

\section{Experiments}

An experimental survey was carried out during summer 2017 along Kronebreen and Blomstrandbreen Glaciers, in order to test and assess the capacity of new low-cost and portable technologies to acquire reliable data in an extreme environment. Among the used technologies, a low-cost and user-friendly probe called ArLoC (Arctic Low-Cost probe) (Figure 1) equipped with depth, temperature and fluorescence of chlorophyll $a$ sensors, pitch, roll and acceleration sensors was tested. The instrument was installed onboard of PROTEUS (Portable RObotic TEchnology for Unmanned Surveys) [11], an autonomous and reconfigurable open frame marine robot which can function like ROV, AUV or USSV. This vehicle is highly modular and allows quick and easy installation and shifting of different payload, so to be reconfigured at every mission according to specific needs. During the survey the vehicle was equipped with the ArLoC and with other probes, as among which the Idronaut 305 plus, in order to compare the low-cost technology performances with 'state of the art' sensors and to obtain a series of reliable data.

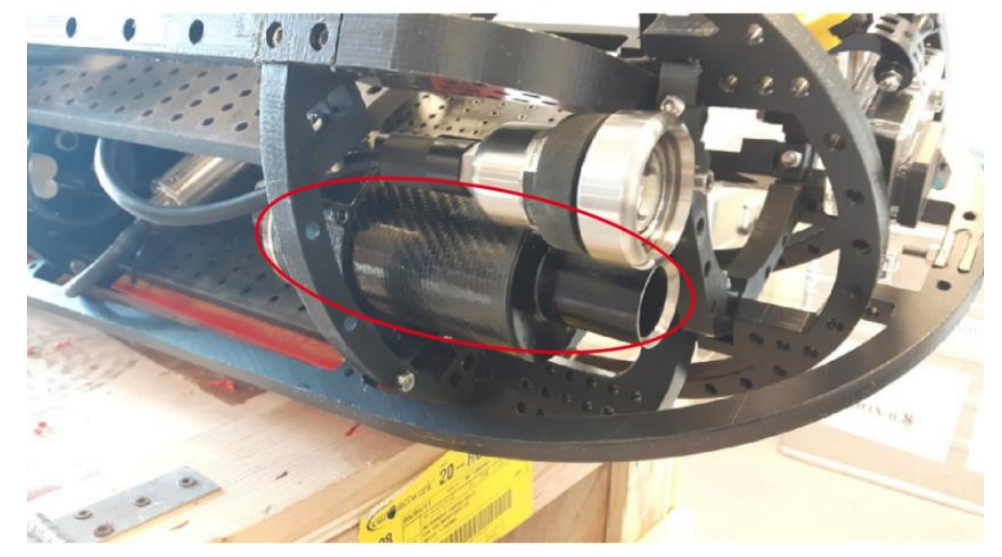

Figure 1. ArLoC installed onboard of PROTEUS.

\section{Results}

In order to assess the performance (and the feature achievement) of the instruments, different transects were performed in the Kongsfjord area (Figure 2a, 2b) and different profiles along the glacier were acquired by $\mathrm{ArLoC}$ and, at the same time, by the Idronaut 305 plus probe. 


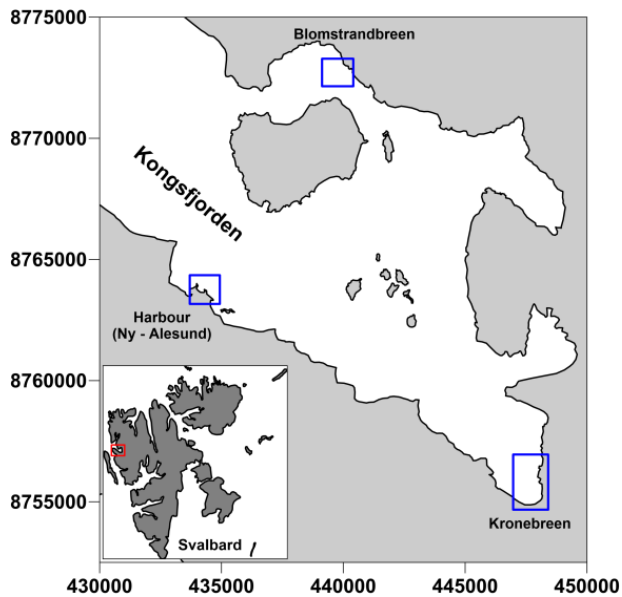

(a)

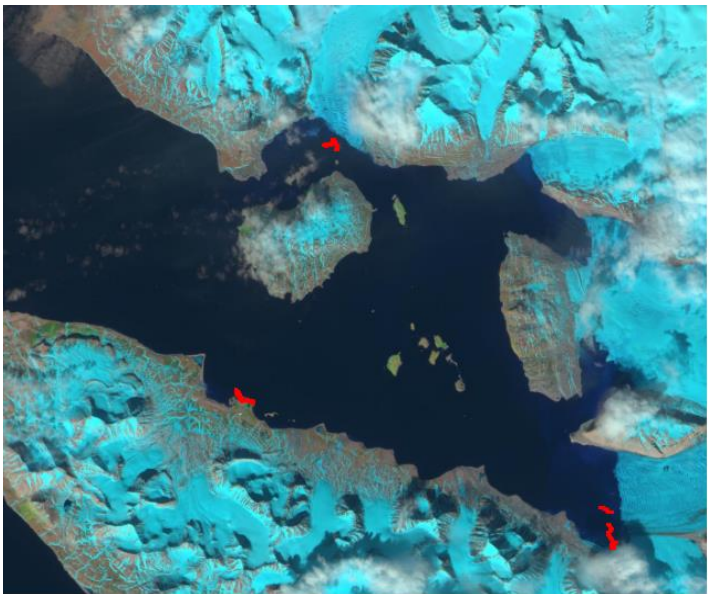

(b)

Figure 2. (a) Three different areas were selected within the Kongsfjorden to perform the surveys; (b) the red points represents the transects trajectories performed by PROTEUS vehicle.

Figure 3a shows the temperature trend in a selected transect along the Kronebreen glacier, while Figure $3 b$ the linear regression between temperature data acquired by ArLoC and Idronaut 305 plus. Figure3b shows a very good correlation between the new technology and the traditional probe with a coefficient $\mathrm{r}^{2}=0.994$, proving the capacity of ArLoC to detect the temperature variations with high accuracy.

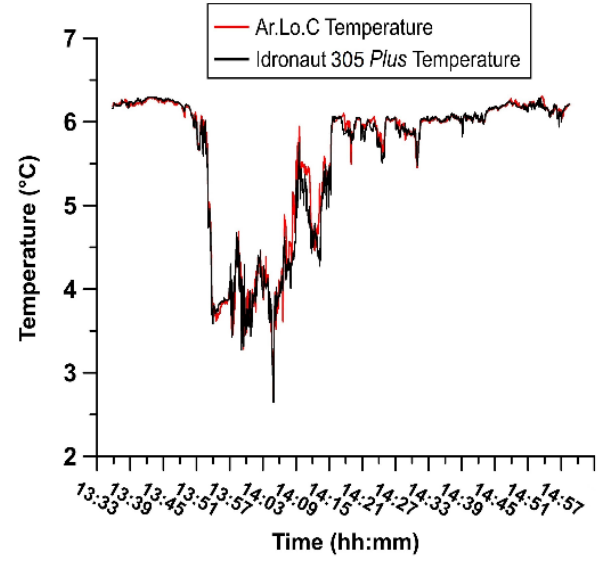

(a)

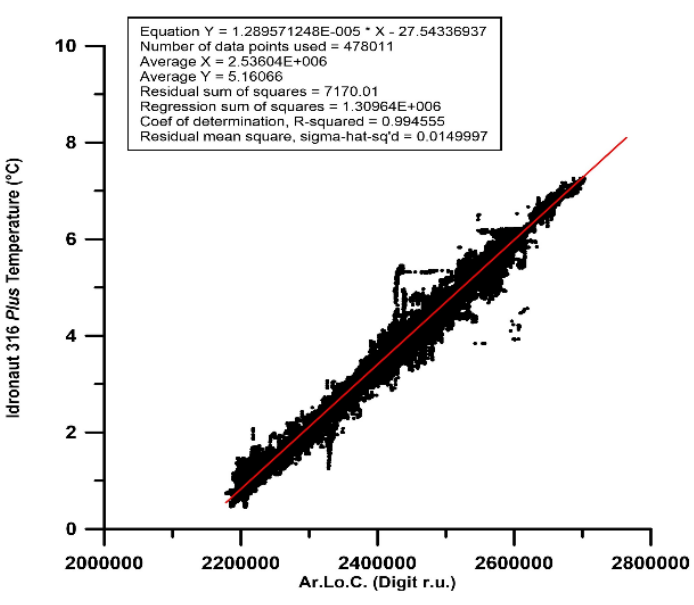

(b)

Figure 3. a) Temperature trend acquired by ArLoC during a transect along Kronebreen Glacier; b) linear regression between Idronaut 305 plus and ArLoC. temperature sensor.

At the same time the instrument acquired fluorescence of chlorophyll $a$, which was previously calibrated in laboratory with spectrophotometric data. 


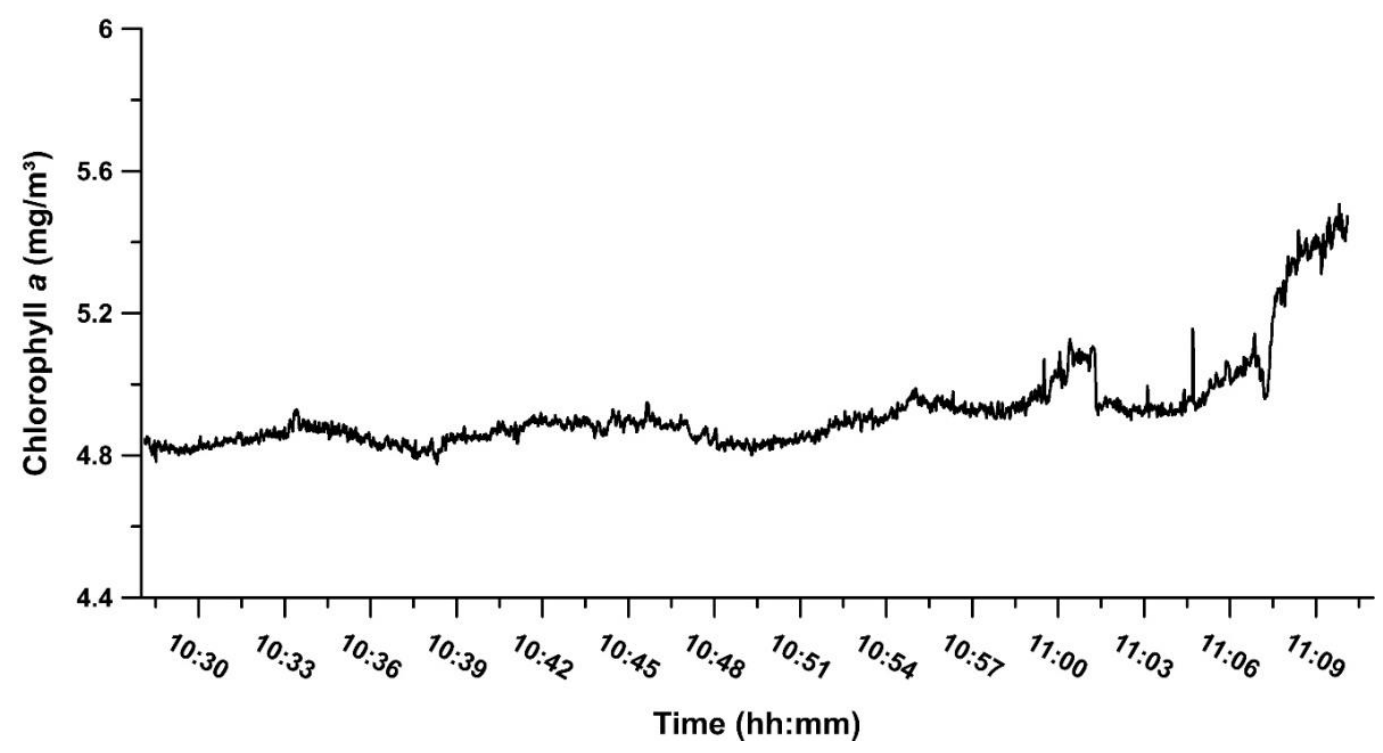

Figure 4. Chlorophyll $a$ trend acquired by ArLoC during a transect along Kronebreen Glacier.

The chlorophyll $a$ data show the capacity of the fluorometer to detect the variations of biomass in a very detailed way. Water samples were collected during the survey for the analysis of chlorophyll $a$ concentration, but the results are not still available to be compared with the instrument acquisitions and no other fluorometer was installed onboard the PROTEUS. Although further processing and comparison are needed, the preliminary results show a good correlation between chlorophyll $a$ concentrations acquired by ArLoC and the concentrations which can be reached in the area [12] , especially in proximity of the glacier.

\section{Conclusions}

During the Arctic Summer 2017, some experimental surveys took place in the Svalbard region, in order to test the performances of a low-cost technology (ArLoC). This technology was easily installed onboard of an unmanned marine vehicle, PROTEUS (Portable RObotic TEchnology for Unmanned Surveys), allowing to describe the temperature and chlorophyll $a$ trends with a high accuracy. The comparison between data acquired by ArLoC technology and the 'state of the art' probe yields strong consistency. The results confirmed the accuracy of the ArLoC temperature sensor when compared with the Idronaut 305 plus and the comparability of chlorophyll $a$ data with the local trends. This low-cost technology and its integration in an unmanned vehicle represents an important progress toward a cost-effective extended monitoring network, in particular in an extreme environment like the Arctic Ocean.

Acknowledgments: The authors wish to thank Giorgio Bruzzone and Edoardo Spirandelli for their fundamental fieldwork during the scientific campaign and contribution to PROTEUS design and development.

Author Contributions: Viviana Piermattei and Alice Madonia collaborated in the development activities, laboratory trials, field tests and data processing. Umberto Mainardi designed and realized electronics and firmware of the instrument. Simone Bonamano and Riccardo Martellucci supported data elaboration. . Gabriele Bruzzone conceived the UVASS project and leaded the 2017 scientific campaign. Angelo Odetti designed naval and mechanical aspects of PROTEUS and participated to the campaign. Maurizio Azzaro supported in situ tests, and Giuseppe Zappalà supported the electronic tests. Roberta Ferretti collaborated in managing the sensors and processing data acquired. Marco Marcelli conceived the idea, designed the instrument and coordinated the projects that funded the sensors and instrument development.

Conflicts of Interest: The authors declare no conflict of interest.

\section{References}

1. Hansen, J., Sato M., Ruedy R., Lo K., Lea D.W. \& Medina-Elizade M. Global temperature change. Proc. Natl. Acad. Sci. 2006, 103, 14288-14293, doi:10.1073/pnas.0606291103. 
2. Wadhams, P. A Farewell to Ice: A Report from the Arctic 2017. Oxford University Press

3. Popova, E., Yool, A., Coward, A.C., Dupont, F., Deal, C., Elliott, S., Hunke, E., Jin, M., Steele, M., Zhang J. Journal of Geophys. Res. 2012, 117, C00D12, 2012, doi:10.1029/2011JC007112.

4. Doney, S.C. Plankton in a warmer world. Nature 2006, 444:695-6.

5. Hallegraeff G.M. Ocean cLimate change, phytoplankton community responses, and harmful algal blooms: a formidable predictive challenge. J. Phycol. 2010, 46, 220-235.

6. Hop, H., Pearson, T., Hegseth, E.N., Kovacs, K.M., Wiencke, C., Kwasniewski, S., Eiane, K., Mehlum, F., Gulliksen, B., Wlodarska-KowalezUK, M., Lydersen, C; Weslawski, JM; Cochrane, S; Gabrielsen, G.W., Leakey, R.J.G., Lonne, O.J., Zajaczkowski, M., Falk-Petersen, S., Kendall, M., Wangberg, S.A., Bischof, K., Voronkov, A.Y., KovaltchoUK, N.A., Wiktor, J. Poltermann, M., di Prisco, G., Papucci, C., Gerland, S. The marine ecosystem of Kongsfjorden, Svalbard. Polar Res., 2002, 21, 167-208.

7. Cisek, M., Colao F., Demetrio, E., Di Cicco, A., Drotzdowska, V., Fiorani, L., Goszczko, I., Lazic V., I.G. Okladnikov, L., Palucci, A., Piechura J., Poggi, C., Sighicelli, M., Walczowsky, W., Wieczorek, P. Remote and local monitoring of dissolved and suspended fluorescent organic matter off the Svalbard. J. Optoelectron. Adv. M. 2010, 12, 1604-1618.

8. Shikai, C.U.I., Jianfeng, H.E., Peimin, H.E., Fang, Z.H.A.N.G., Ling, L.I.N., Yuxin, M.A.. The adaptation of Arctic phytoplankton to low light and salinity in Kongsfjorden (Spitsbergen). 极地研究， $2012 ， 23(1-$ English), 19-24.

9. IOC/UNESCO, 2010. Why monitor the Arctic Ocean? Services to society from a sustained ocean observing system.

10. Trevathan, J., Johnstone, R., Chiffings, T., Atkinson, I., Bergmann, N., Read, W., Theiss, S., Myers, T., Stevens, T. SEMAT-The next generation of inexpensive marine environmental monitoring and measurement systems. Sensors 2012, 12, 9711-9748.

11. Bruzzone, G., Odetti, A., Caccia, M. The UVASS project (Unmanned Vehicles for Autonomous Sensing and Sampling) - Collecting data near marine glacier fronts in Kongsfjorden by using unmanned marine vehicle., Sea Technol. 2017, November Issue.

12. van De Poll, W.H., Maat, D.S., Fischer, P., Rozema, P.D., Daly, O.B., Koppelle, S., Visser, R.J.W., Buma, A.G. (2016). Atlantic Advection Driven Changes in Glacial Meltwater: Effects on Phytoplankton Chlorophyll-a and Taxonomic Composition in Kongsfjorden, Spitsbergen. Frontiers in Marine Science, 3, 200.

(C2017 by the authors; licensee MDPI, Basel, Switzerland. This article is an open access article distributed under the terms and conditions of the Creative Commons Attribution (CC-BY) license (http://creativecommons.org/licenses/by/4.0/). 